\title{
Coping with drought: the experience of water sensitive urban design (WSUD) in the George Municipality
}

\author{
Naomey Lottering', Danie du Plessis² and Ronnie Donaldson'* \\ 'Department of Geography and Environmental Studies, University of Stellenbosch, P/Bag X 1, Matieland, 7602, South Africa \\ ${ }^{2}$ CRUISE (Centre for Regional and Urban Innovation and Statistical Exploration), University of Stellenbosch, P/Bag X 1, Matieland, 7602, South Africa
}

\section{ABSTRACT}

This study investigated the extent of Water Sensitive Urban Design (WSUD) activities in the George Municipality in the Western Cape Province, South Africa, and its impact on water consumption. The WSUD approach aims to influence design and planning from the moment rainwater is captured in dams, to when it is treated, and reticulated to consumers, and extending to the point of wastewater re-use, as well as stormwater use. The study identified 8 WSUD sub-activities stemming from 4 main WSUD activities, implemented by the George Local Municipality. Water debtors' data were sourced in order to measure the effect of 3 of the 8 WSUD sub-activities on water consumption in selected areas. The analysis confirmed that the three WSUD sub-activities had a short-term impact on reducing water consumption in the suburbs where they were implemented. It is recommended that the municipality focus on improved planning and implementation of a diverse range of WSUD activities and implementing information and monitoring systems to evaluate the impact of these measures.

Keywords: Drought relief strategies, George Municipality, integrated urban water management, South Africa, water sensitive urban design

\section{INTRODUCTION}

The unsustainability of urban water resource management was first addressed by the concept of integrated urban water management (IUWM), formulated by the Urban Water Resources Research Council of the American Society of Civil Engineers during the late 1960s and early 1970s (Mitchell, 2006). Various countries across the world responded with their own concepts, such as the USA with 'low-impact development', the UK with their 'sustainable urban drainage system' and New Zealand with 'low impact urban design and development'. Australia responded with 'water sensitive urban design' (WSUD), a term coined by a group at Murdoch University in Perth, Western Australia. WSUD provides guidelines on how to improve water infrastructure design in the natural and built environment (Fane, 2005; Morison and Brown, 2011; Ashley et al., 2013). WSUD promotes the implementation of independent or main activities on various scales from small (1 house) to large (cityscale) urban developments which include new developments, existing and brownfield sites (Donofrio et al., 2009). The main WSUD activities are stormwater/drainage management, re-use of water, demand reduction techniques and greenroof installation (Donofrio et al., 2009).

This study investigated the extent of WSUD's impact in a South African context by examining the George Municipality in the Eden District, Western Cape Province. Contrary to the fact that George is not seen as a water-deficient area (George Local Municipality, 2008:44) especially after severe floods in the mid-2000s (Tempelhoff et al., 2009), the municipality was declared a drought disaster area in November 2009, along with many others in the Eden District (Western Cape Province,

To whom all correspondence should be addressed

邑 +27 21 808-2395; e-mail: rdonaldson@sun.ac.za

Received 13 March 2013; accepted in revised form 14 November 2014.
2009).The study area experienced a 1 in 130-year drought (Gunning, 2009), with records showing that from January to December 2009 it received $100 \mathrm{~mm}$ less rainfall than in 1946, the lowest recorded rainfall for the same period (Mooiman, 2010 , pers com). Though there is more than one definition of a drought, the George drought is best defined as a meteorological drought, which is a lack of precipitation over an area for a period of time.

\section{Overview of WSUD activities}

Typically, main WSUD activities and strategies include the following: stormwater/drainage management, re-use of water, demand reduction techniques and greenroof installation, with each main activity having its own set of sub-activities (Australia, 2001; Mishra and Singh 2010). The first main activity, stormwater management, can range from the retention of stormwater for filtration into aquifers, to the filling of wetlands and lakes for recreational use (Hoyer et al., 2011; Echols and Pennypacker 2008). The quantity and quality of water being received by the stormwater system needs to be managed (Lloyd, Wong and Porter, 2002; Allison, Chiew and McMahon, 1997) and can be done by using 4 different methods or sub-activities. These include rain sensors - which stop additional water from entering the stormwater system, (Donofrio et al., 2009), rainwater harvesting tanks which store rainwater received from the roof gutters (roof run-off), (Tam, Tam and Zeng, 2010), and drought-tolerant landscaping practices that reduce irrigation run-off and gradually release the retained (stored) water into the ground to recharge groundwater (McAlister, 2007). The first sub-activity, known as 'source control elements', not only reduces the quantity of water entering the stormwater system but also prevents pollutants from entering water bodies and groundwater (Donofrio et al., 2009).

The second activity, the re-use of water, can be applied to both wastewater and stormwater. Although wastewater and 
stormwater can be re-used separately, they are often re-used in conjunction with each other. An option provided in the Australian context is to be connected to a 'reticulated recycled water supply', supplied by local authorities. This system provides recycled water as an alternative source of water, for non-potable use only, via a pipeline with a tap for each user who opts to use it (McAlister, 2007). Stormwater is reused via rainwater harvesting tanks which allows for the re-use of water for non-potable purposes (Speers and Mitchell, 2000).

The third activity, water demand management (WDM) or potable water demand reduction techniques, ensures that water use is reduced, through reduced leaks, reduced wastewater flows, and the better awareness of consumers of the environmental and financial value of water. WDM can be applied in conjunction with other water conservation techniques and includes both the demand and supply side of water management, such as the retrofitting of appliances, leakage detection and fixing (McAlister, 2007) and localised sanitation management (Newman, 2001; Kenney et al., 2008; Sharma and Vairavamoorthy 2009; Wolfe, 2009a; Wolfe 2009b). The retrofitting of appliances can include putting in low-flow tap fittings, low-flush or dual-flush toilets, installing irrigation systems that can be controlled electronically (Newman, 2001) and the use of water-efficient appliances such as dishwashers. Localised sanitation management, which is used primarily by small-sized homes, includes septic tank systems, aerobic treatments and composting toilets (Newman, 2001).

The fourth activity, greenroof installation, is a specially designed roof covered with vegetation supported by a substrate layer varying in depth (Castleton, 2010) The structural needs for the roofing system include waterproofing, root barriers, and insulation underlying the substrate layer (Thomas and Thomas, 2003). Two types of rooftop gardens or greenroofs are being promoted in Australia. The first, and more maintenance-free rooftop garden, is the 'extensive greenroof', which often consists of drought-resistant plants (desert species) which need little or no irrigation. The second type is the intensive greenroof', which needs more care from professionals because often a bigger plant selection is used and more maintenance is required (Thomas and Thomas, 2003). A third type of greenroof is the 'vertical garden', the chief benefit and purpose of which is to insulate buildings (Thomas and Thomas, 2003). Other environmental benefits of a greenroof are retaining of stormwater, air quality improvement and preservation of biodiversity in the urban setting (Thomas and Thomas, 2003).

\section{METHODOLOGY}

A qualitative and quantitative approach was followed in the study. Firstly, a qualitative assessment was done by means of assessing the policies and strategies implemented by the municipality to cope with the drought. Interviews were held with key stakeholders dealing with the drought at municipal level, which included managers and senior technicians. Evidence of the implementation of 7 sub-activities was found, namely, awareness campaigns, emergency tariffs, water restrictions, localised sanitation, leakage detection, wastewater re-use and the maintenance of the stormwater system.

Secondly, debtors' data were used in specific areas identified, and regression modelling was applied to quantify the extent of implementation. The potential impact of the three (the awareness campaign, the emergency tariff structure and water restrictions) measurable WSUD sub-activities was evaluated by using debtors' data for a selected number of areas over a 42-month period. Usable data were only available from January 2008 and it was necessary to have data before the drought, during the drought and after the drought. The municipality reported that by February 2011 the dams in the town were sufficiently full to provide for demand (McGown, 2011). Obtained from the Finance Department of the George Municipality, the debtors' data reflect the water accounts per debtor (account holder), which includes the name of the debtor, the erf number registered under the debtor's name, the address under which the erf is registered, the actual meter reading, the change in water consumption from month to month (the current months reading less the previous months reading), and the suburb in which each debtor resides. This change in water consumption will simply be known as 'consumption' henceforth (the name given in the debtors' data) and will be used to measure the impact of a WSUD activity over the study period. The George Municipality is divided into wards with each ward having a set number of suburbs and each suburb assigned a suburb identification (sub-ID) number. Each sub-ID, representing a suburb, consists of erfs with a corresponding debtor for each (it is assumed that most erfs are occupied by a debtor) and with each erf differing in size and structure. For example, Sub-ID 40 with its large pockets of informal dwellings is occupied by 4273 debtors and Sub-ID 7, an area dominated by formal dwellings, is occupied by 92 debtors. It should be noted that the number of debtors is only a close approximation of the number of erfs, since, for example, one erf can be occupied by two or more debtors. Nevertheless, sub-IDs are the smallest unit of spatial aggregation in the municipality, at which the data could be analysed. The dominant method of analysis was to compare low- and high-income sub-IDs and thus wards were sorted and ranked according to the monthly average income of residents. The reasoning behind the choice of target groups stemmed from research on water consumers which suggested that high-income and low-income users have different wateruse behaviours (Veck and Bill, 1998). If this is the case, it can be assumed that these two income groups would respond differently to water use reduction measures. However, if both income groups have similar responses to the measures, it would suggest that, in the case of a positive response, WSUD interventions are effective in all demographics, whereas if the response to WSUD is negative, it would suggest the opposite. If the two groups respond differently, it would suggest that WSUD is only effective in certain demographics and that the implementation of WSUD should therefore take this into account (Veck and Bill, 1998). The objective, however, was not to compare demographics as an end in itself, but to examine the extent of the impact that WSUD has on the whole area.

The debtors' data identifies indigent or poor residents; where it was found that indigent debtors were resident in higher income sub-IDs, these were excluded from the higher income sample sub-IDs, so as to fully analyse the water consumption patterns of higher income debtors. Similarly, only debtors identified as indigent were included in the selected poorer sample areas. Furthermore, debtors who had not occupied the property (erf number) for the full 42 months were also excluded from the sample, thus eliminating the need to take population growth into account, since the same set of debtors was used from month to month. Lastly, to avoid spurious results, debtors were excluded where human error in data capturing was evident. For the purpose of comparison, 4 sub-IDs were selected from the high-income wards and 4 sub-IDs from the low-income wards. For the high-income sub-IDs, 1342 debtors were identified, of which only 807 were included in the sample, representing $60 \%$ 
of all debtors identified. The low-income sub-IDs presented a problem because only 3 sub-IDs - 40, 41 and 42 - could be identified, as a result of Sub-ID 40 being spread across more than one ward. Furthermore, Sub-ID 41 only has 12 indigent debtors. To solve the problem, Sub-ID 41 was excluded and 3 random samples were taken from Sub-ID 40 (with its relatively large debtor population size) to act as a proxy for the 3 additional sub-IDs needed to complete the list of 4 indigent subIDs. Of the 4410 indigent debtors identified, only 2621 debtors were included in the sample, representing $59 \%$ of all debtors.

\section{ANALYSIS AND RESULTS}

\section{Qualitative analysis}

The study examined the strategies, plans and bylaws of the George Municipality in order to identify WSUD activities and determine if the municipality had an enabling environment for WSUD implementation. Three distinct policy and strategy time periods were identified, namely, the periods prior to the start of the drought, during the drought and after the drought.

Prior to the 2009 drought, the municipality approved the George Spatial Development Framework (GSDF) of 2008, Integrated Development Plan of 2009/10, and the Water Services Development Plan (WSDP) of 2009/10. Despite there being no specific emphasis on actions to be taken when there is a chronic lack of water, all three documents stipulate general plans for water demand management by outlining some cautionary measures or strategies. Identified strategies include increased water abstraction via extra pumping stations; greywater recycling and wastewater reclamation; water conservation awareness campaigns; leak detection and fixing; and stormwater system cleaning. The GSDF emphasized the need for measures such as the use of treated effluent from Waste Water Treatment Works (WWTWs), not only for irrigation but also for filling the Garden Route Dam; the harvesting of stormwater; the recycling of greywater; the installation of watersaving devices, and, possibly, the design of a closed wastewater treatment system for domestic effluent. The IDP refers to the need for a water-wise campaign, and aims to repair $98 \%$ of burst pipes and clean $10 \%$ of manholes. Rainwater tank installation was provided in 2 wards. The municipality adopted the WSDP of 2009/10 with a Water Demand Management Strategy, identifying various measures to be implemented (Nel, 2010). These include measures such as the implementation of a new water cost and pricing strategy, the introduction of a leakage management programme, the promotion of water conservation products, and the reuse of wastewater.

The drought forced the municipality to provide water and deal with the demand, which resulted in the Drought Status Report, the Drought Management Policy, a Water Demand Management Strategy, and a Water Services Bylaw. As a response to the drought in 2010 the municipality published a status report which stated that investigations into future water resource supply were complete by April 2007, and that water demand management was one of the supply options as well as the use of treated effluent (Mooiman, 2010). As a third option the municipality considered enforcing the compulsory installation of rainwater harvesting tanks for new developments, even though the municipality could not afford to subsidise the installations. The document highlights the tight restrictions that have been in place since 2009 and the intensification of the awareness campaign since the second half of 2009. The municipality initiated various activities including contacting high-volume water consumers to indicate that their water could be restricted by the municipality if high consumption continued; public toilets receiving hippo bags/bricks in the cisterns; staff in tourist accommodation facilities and prisons being educated about water saving, and disconnecting of taps and showers on the beaches. The drought management policy was approved by council to ensure that an appropriate policy would be in place to cope with future drought situations, during periods of low rainfall or a drop in water resources (Mooiman, 2010).

Plans for future water requirements are addressed in the Water Services Development Plan of 2010/11. The plan stipulates the installation of water meters for each dwelling, retrofitting water-saving appliances, installing rainwater harvesting tanks on all new developments, installing bulk water meters and monitoring bulk pipelines. The $2010 / 11$ plan also mentions private water demand management options, such as encouraging private property owners to install greywater systems. These are, however, expensive and might give cause for health concerns (Mashicila, 2010). For the future, the municipality is also considering taking a project for the re-use of effluent to the second phase, as Phase 1 is already in place (Mashicila, 2010). Other measures include restrictions limiting irrigation to specific times of day and disconnection of automaticallyflushing urinals.

As mentioned above, a total of 7 WSUD sub-activities were implemented in George during the study period, only 3 of which could be quantified, namely, the awareness campaign, emergency water tariffs, and revised water restrictions. The awareness campaign was initiated when the area was declared a drought-stricken area in October 2009. Initially this consisted of weekly updates about the dam levels via notice boards in town. A full-blown awareness campaign was then launched by a task team for all towns in the Eden District. Billboards were erected at the main entrances to the towns, streetlamp posters were put up, leaflets were handed out at roadblocks during the December holidays, the local radio station ran a radio campaign, and a water conservation jingle was created. This jingle was also used at the municipality switchboard for callers placed on hold. Interviews regarding the water situation were held twice a week on the radio with Eden District Municipalities' staff members, and the local fire department used a truck to play the water conservation jingle in the townships (McGown, 2011). In addition, water-saving tips were provided via the radio station every Friday, a newspaper campaign was run for 6 months in a number of newspapers, and banner strips were designed by the Eden District Municipality communication department (McGown, 2011). A George Task Team - separate from Eden District's awareness campaign initiative - was set up, consisting of senior managers, disaster management, and the engineering and accounting departments. The awareness campaign concluded in January 2011 when the drought was officially declared over (McGown, 2011). Additional awareness activities included an exhibition stand showcasing water-saving devices and information on the Water Augmentation Plan, and a PowerPoint presentation about the municipality's role in water conservation and how people can help to save water during the drought.

Water restrictions were enforced in the George Municipality from 7 December 2009 (George Local Municipality, 2009c). Restriction of water use included prohibition of the watering of gardens and sports fields with potable water as well as the banning of car-washing. The cleaning of hard surfaces with water and the filling of swimming pools were also 
prohibited. Some exemptions were however granted, especially for businesses. The municipal council decided to ease restrictions during a meeting on 25 November 2010, after the area had received some rainfall (George Local Municipality, 2011).

Emergency water tariffs were implemented from 27 November 2009 to 27 December 2010 (George Local Municipality, 2011). The tariffs were imposed on the whole town, including the domestic, commercial and industrial water-use sectors. The emergency tariff structure was published on the municipality website during the drought months.

\section{QUANTITATIVE ANALYSIS}

To get a better understanding of how the above measures were experienced in George at the time, high income and lower income suburbs were compared. Two sets of data were generated for this purpose: average consumption per month and percentage change in consumption. The percentage changes in consumption were generated for the months of September, October, November and December during the years 2008, 2009 and 2010. This was to simplify the analyses for the sake of comparison. The awareness campaign started in October whilst the restrictions and tariffs started in November and December. September was added because it was an initial starting point for comparison.

Water usage by high-income debtors over the 42-month period, per debtor, per month, was $183 \%$ higher than for low-income users (or almost 3 times as much). Furthermore, whereas high-income debtors generally have monthly consumption levels greater than $20 \mathrm{k} \ell$ during non-drought months, low-income debtors have monthly consumption levels that vary between 7 and $9 \mathrm{k} \ell$ during drought and non-drought months. The highest-income suburb, Sub ID-7, had consumption figures between 30 and $50 \mathrm{k \ell}$. For example, Sub-ID 7 peaks at $70.5 \mathrm{k} \ell$ in February, 2009, and troughs at $25.3 \mathrm{k} \ell$ in June, 2010.

Since the data only stretches from the first month of 2008 until the $6^{\text {th }}$ month of 2011, the time-period is too short to make a useful comparison of annual percentage changes in consumption; therefore the consumption data have been calculated and compared on a quarterly basis and monthly basis. The quarterly figure is calculated as the percentage change in consumption from one quarter to the next and the monthly figures are calculated as the actual average consumption per debtor from one month to the next.

As illustrated in Fig. 1, there was a noticeable drop in the percentage change in consumption by high-income debtors, from $2 \%$ in the first and second quarter of 2009 to $1.7 \%$ in the $3^{\text {rd }}$ quarter of 2009 , reaching a low of $1 \%$ in the second and third quarter of 2010, and thereafter remaining steady at $1.1 \%$ from the $4^{\text {th }}$ quarter of 2010 till the $2^{\text {nd }}$ quarter of 2011 . A comparison of all $3^{\text {rd }}$ quarters reveals a significant drop in the percentage change in consumption, with the $20083^{\text {rd }}$ quarter consumption rising by $1.9 \%$. It is interesting to note that the drop in the percentage change in consumption started in the $3^{\text {rd }}$ quarter of 2009 whereas the awareness campaign started in the $4^{\text {th }}$ quarter. The only assumption that can be made is that the media started reporting on the possible drought, thus creating awareness of the drought prior to the awareness campaign. This can, to a certain extent, be validated by an online article dated 8 September 2009, which quotes the Eden District disaster manager Gerhard Otto as saying that 'the George Dam was only $30 \%$ full and dropping by $1 \%$ every week' with the possibility of George running 'out of water by mid-January' (Mckune, 2009).
High Income Consumption: \% Change

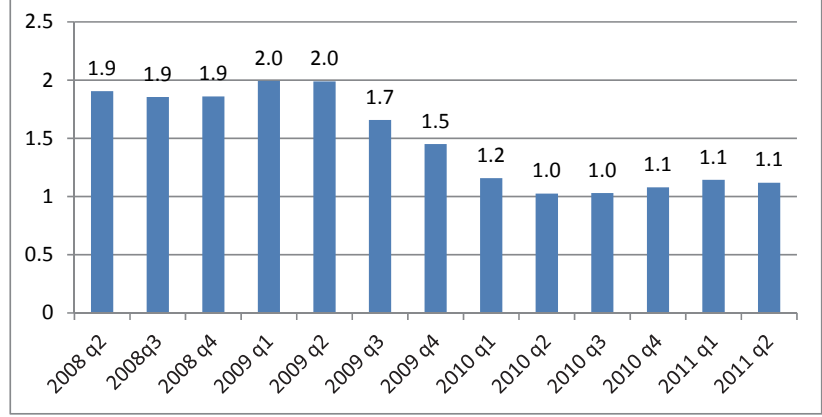

Figure 1

Percentage change in quarterly total consumption for high-income debtors (Source: extracted from data provided by George Municipality Finance Department)

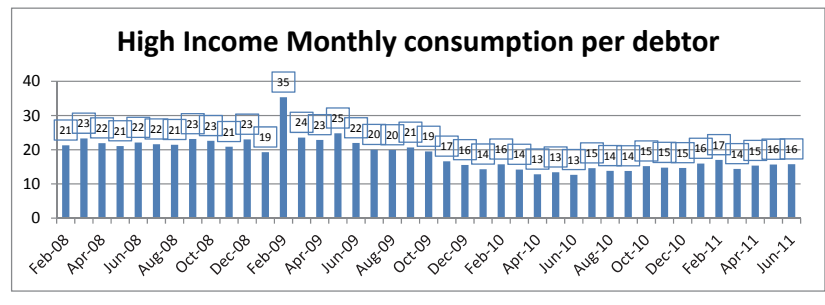

Figure 2

Monthly consumption per debtor for high-income debtors (Source: extracted from data provided by George Municipality Finance Department)

A monthly comparison, as illustrated in Fig. 2, shows that consumption in the high-income areas started dropping to below $20 \mathrm{k} \ell$-debtor ${ }^{-1}$ from October 2009, the month in which the awareness campaign commenced. The municipality's objective of reducing consumption to below $15 \mathrm{k} \ell \cdot$ debtor $^{-1}$ was achieved in January 2010, when consumption stood at $14.2 \mathrm{k} \ell$.debtor ${ }^{-1}$. During the campaign period, consumption remained at or below $15 \mathrm{k} \ell$, with February 2010 being the only month in which consumption was greater than the limit, at 16 $\mathrm{k} \ell$. However, it should be noted that February is a peak month with the highest consumption levels. Consumption levels started to increase to levels greater than $15 \mathrm{kl}$ in January 2011, the month in which the awareness campaign ended. However, albeit remaining, on average, below $15 \mathrm{k} \ell$, consumption started a slight but steady increase from the month of June 2011 onward, which could be interpreted as the debtors' response to the Eden Water Crisis report for July 2010 which mentions that the municipality was already at low risk, with more than 6 months' supply of water (Summers, 2010).

Monthly comparisons for low-income debtors were difficult since there is no noticeable pattern that suggests that there was a response to the consumption reduction measures. However, the quarterly comparison (Fig. 3) suggests a possible response, when percentage change in consumption went from $2 \%$ in the $3^{\text {rd }}$ quarter of 2009 to $1.8 \%$ in the $4^{\text {th }}$ quarter of 2009 , then $1.7 \%$ in the $3^{\text {rd }}$ quarter of 2010 , reaching a low of $1.6 \%$ the second quarter of 2011. Prior to this drop (during the $20094^{\text {th }}$ quarter), the percentage change in consumption hovered at or above $2 \%$.

Lastly, the municipality claimed that water consumption was reduced by $44 \%$ when comparing the months of February 2009 and February 2010. The results of the analysis 


\section{Low Income Consumption: \% Change}

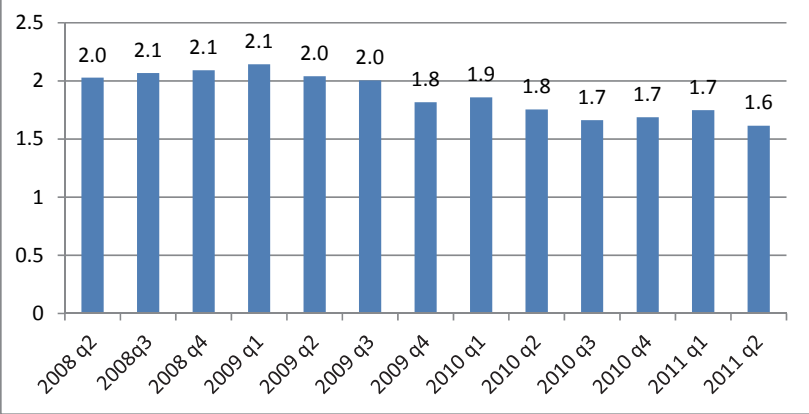

Figure 3

Percentage change in quarterly total consumption for low income debtors (Source: extracted from data provided by George Municipality Finance Department)

in the selected areas however indicated significant differences between high- and low-income areas. In the low-income subIDs water consumption was reduced by $27 \%$ over this period, while the decrease in the sampled high-income areas was 55\%. This can be attributed to the fact that water consumption in the low-income areas had always been below $15 \mathrm{k \ell} \cdot$ debtor $^{-1} \cdot \mathrm{month}^{-1}$ (in water crisis reports the municipality aimed to reduce all below $15 \mathrm{kl}$ ) and that the municipality's interventions thus had no significant impact on the reduction of water consumption of users in low-income areas. In total, when summing the lowand high-income consumption figures, there was a reduction of $49 \%$, which not only verifies the claim made by the municipality, but suggests the improvement to be greater.

To test the validity of, and add statistical value to, the results above, a Stata regression model was applied to the sample data. A regression is simply a way to establish how the introduction of an independent variable will impact on the behaviour of a dependent variable, thus being able to predict or estimate the average value of the dependent variable if the independent variable is introduced (Gujarati, 2004).

Using the cross-sectional sample of 2985 debtors, each with a time-series of 41 months or observations, the data were combined to generate a total of 122385 pooled observations. Setting consumption as the dependent variable and the rest (awareness campaign, restrictions, tariffs) as independent variables, a regression was run at a $95 \%$ confidence level, and only the relationships between 'awareness campaign' and 'consumption' and 'tariffs' and 'consumption' were found to be statistically significant. This could be attributed to the presence of multicollinearity, with a $94 \%$ correlation between restrictions and tariffs. Furthermore, it is difficult to distinguish between restrictions and tariffs since they were implemented during the same period. Restrictions ran between 7 December 2009 and 10 November 2010, and tariffs ran between 27 November 2009 and 27 December 2010.

Bivariate regression was then run for each independent variable and their lags. It was found that awareness, lagged by 2 periods, had the most significant impact on consumption, whereas this was true for tariffs when lagged by zero periods and restrictions when lagged by 1 period. In other words, although the awareness campaign had an immediate impact on water consumption, it took 2 months for the awareness campaign to have a maximum impact whereas tariffs had an immediate (zero-lagged) maximum impact on consumption and restrictions a 1-month lag.
Regressing consumption against awareness lagged by 2 periods, and tariffs lagged by zero periods, it was found that the awareness campaign led to a $1.65 \mathrm{k} \ell \cdot$ user $^{-1} \cdot \mathrm{month}^{-1}$ decrease in consumption. The implementation of tariffs had a much more subdued effect in that it led to a $0.44 \mathrm{kl}$ decrease in consumption, per user, per month. Running a similar regression for high-income debtors, with a cross-sectional sample of 680 debtors, each with a time series of 41 months, to generate a combined sample of 27880 observations, we determined that the awareness campaign reduced water consumption by $5.51 \mathrm{k} \ell$ whilst tariffs led to a reduction of $1.57 \mathrm{k} \ell$. Running a similar regression for low-income debtors with a crosssectional sample of 2305 debtors, each with a time series of 41 months, to generate a combined sample of 94505 pooled observations, we found that the awareness campaign reduced water consumption by $0.52 \mathrm{k} \ell$ whilst tariffs led to a reduction of $0.10 \mathrm{k} \ell$.

To make sense of the difference between high- and lowincome debtors, consumption was regressed against income (using dummy variables), and we found that over the sample period high-income users have a unit consumption value of $9.53 \mathrm{k \ell}$ greater than low-income users.

\section{DISCUSSION}

The results of the analysis indicated that three of the WSUD sub-activities (tariff changes, restrictions and the awareness campaign) had a short-term effect on reducing water consumption.

However, looking at high-income water users, the data suggest that the sub-activities had a possible longer-term effect by keeping water consumption below the $20 \mathrm{k} \ell \cdot$ debtor $^{-1} \cdot$ month $^{-1}$ mark. Whereas water consumption started to rise after it was announced that the municipality was at low risk in July 2010, it only rose to $16 \mathrm{k} \ell$ by the end of the study period in the nondrought month of June 2011, $6 \mathrm{k} \ell$ less than the $22 \mathrm{k} \ell$ for the same month in 2008 and 2009.

In the low-income wards the effect of the WSUD activities was limited, since these areas already used less than the targeted $15 \mathrm{k} \ell$. However, the percentage change in quarterly total consumption for low-income debtors, suggested that the water use reduction measures did have some impact on the water use behaviour of low-income debtors.

Regression analysis was applied to verify the results above. The awareness campaign, taking 2 months to have a maximum impact, reduced consumption by $1.65 \mathrm{k} \ell$. Although it is hard to distinguish between the two, tariffs had an immediate maximum effect and restrictions took 1 month to have a maximum impact. Tariffs were found to reduce consumption by $0.44 \mathrm{k} \ell$, but, since tariffs acts as a proxy for both tariffs and restrictions, it is not possible at this stage to say which sub-activity had the most significant impact. The regression analysis also confirms that the response from high-income water users was substantially greater when compared to low-income users. Consumption by high-income users decreased by $5.51 \mathrm{k} \ell$ and $1.57 \mathrm{k} \ell$ due to the awareness campaign and the tariff proxy, respectively. In low-income areas, the awareness campaign and tariff proxy reduced consumption by $0.52 \mathrm{k} \ell$ and $0.1 \mathrm{k} \ell$, respectively. Furthermore, high-income water users used $9.53 \mathrm{k} \ell$ more water than low-income users, during the entire study period.

The overall analysis does validate the use of WSUD activities as a means of reducing water use, although only limited sub-activities were analysed. It should be noted, however, that though tariffs and water restrictions had some significant 
impacts on water use, the awareness campaign had a much larger impact on the behaviour of water users. This suggests that policy makers should not underestimate the value of education in influencing the behaviour of water users. In addition, when considering implementing water reduction activities, it should be taken into consideration that intervention should be primarily aimed at high-income water users, since they are seemingly the demographic groups most likely to exhaust water resources.

Lastly, it should be noted that the remaining sub-activities (localised sanitation, leakage detection and fixing, wastewater reclamation, and stormwater quantity and quality management) were not quantifiable due to a lack of sufficient or useable data, suggesting either data-capturing deficiencies or operational deficiencies or both. Furthermore, stormwater quantity and quality management was also not measured since capturing of stormwater was not prioritised. This would suggest that the municipality needs to find ways to improve either its data capturing or operational capacity (or both), in order to fully monitor the effectiveness of these activities.

\section{CONCLUSION AND RECOMMENDATIONS}

The study found that the three sub-activities, namely, the awareness campaign, tariffs and restrictions, significantly reduced consumption, helping the municipality achieve its goal of reducing consumption to below $15 \mathrm{k} \ell$. However, due to already low water use patterns in low-income areas, the impact of these sub-activities was not substantial although there was some impact. High-income areas, which use almost 3 times as much water as low-income users, responded very positively and significantly to the sub-activity implementation. Furthermore, the contribution of the awareness campaigns was far more substantial than that of the tariffs and restrictions, suggesting that educating the water user produces more positive results than coercive methods. Water is a precious commodity that can become scarce if not managed in a manner that mitigates a possible drought scenario. Australia's WSUD was a response to an existing drought, but South Africa, with its progressive legislation, can implement its own WSUD alternatives before it too suffers what Australia is already experiencing. George was thought to be an area where a drought scenario would be improbable, but this was not the case. This paper hopes to contribute to a body of literature that aims to mitigate a drought scenario for the entire South Africa by determining whether WSUD activities can contribute towards this mitigation. With the continuation of similar research, South Africa will be able to protect itself against the possibility of a drought scenario and still succeed in sustaining the environment, the economy and its people.

\section{ACKNOWLEDGEMENTS}

SANPAD is thanked for their financial support.

\section{REFERENCES}

ALLISON R, CHIEW F and McMAHON T (1997) Stormwater gross pollutants. Industry Report 97/11. Cooperative Research Centre for Catchment Hydrology, Monash University, Melbourne.

ASHLEY R, SHUCKSMITH J, BLANKSBY J, SHARP L, TAIT S, SHAFFER P and STAM J-M (2013) Water sensitive urban design in a European context. In: Water Sensitive Urban Design 2013: WSUD 2013. Engineers Australia, Barton, ACT: 209-219. URL:
http://search.informit.com.au/documentSummary; $\mathrm{dn}=8687089415$ 49015;res=IELENG (Accessed 15 February 2014).

AUSTRALIA (2001) Guidelines for implementing total management planning, asset management: water demand management implementation guide. Department of Environment and Resource Management (DERM), Australia. URL: http://www.derm.qld.gov. au/compliance/wic/pdf/guidelines/tmp/2001 guidelines/implementation/asset 01.pdf (Accessed 20 July 2012).

CASTLETON HF, STOVIN V, BECK SBM and DAVISON JB (2010) Green roofs; building energy savings and the potential for retrofit. Energ. Buildings 42 (10) 1582-1591.

DONOFRIO J, KUHN Y, McWALTER K and WINSOR M (2009) Water-sensitive urban design: An emerging model in sustainable design and comprehensive water-cycle management. Environ. Pract. 11 (3) 179-189.

ECHOLS S and PENNYPACKER (2008) From stormwater management to artful rainwater design. Landscape J. 27 (2) 268-290.

FANE SA (2005) Planning for sustainable urban water: Systemsapproaches and distributed strategies. PhD thesis, University of Technology, Sydney.

GEORGE LOCAL MUNICIPALITY (2008) George Spatial Development Framework. George Municipality, George.

GEORGE LOCAL MUNICIPALITY (2009) Revised water restrictions notice. George Municipality, George.

GEORGE LOCAL MUNICIPALITY (2011) Change in emergency tariff and restriction notice. George Municipality, George.

GUJARATI D (2004) Basic Econometrics (4 ${ }^{\text {th }}$ edn.). McGraw-Hill, Chicago. 1004 pp.

GUNNING E (2009) Eden District Disaster Area, News 24 Online, 12 November 2009. URL: http://m.news24.com/news24/southafrica/ news/eden-district-a-disaster-area-20091112 (Accessed 12 June 2010).

HOYER J, DICKHAUT W, KRONAWITTER L and WEBER B (2011) Water Sensitive Urban Design: Principles and Inspiration for Sustainable Stormwater Management in the City of the Future. Jovis Publishers, Berlin.

KENNEY DS, GOEMANS C, KLEIN R, LOWREY J and REIDY K (2008) Residential water demand management: Lessons from Aurora, Colorado. J. Am. Water Resour. Assoc. 44 (1) 192-207.

LLOYD SD, WONG THF and PORTER B (2002) The planning and construction of an urban stormwater management scheme. Water Sci. Technol. 45 (7) 1-10.

MASHICILA S (2010) Personal communication, 29 September 2010. Mr Simphiwe Maschicila, Department of Water Affairs, Western Cape Province, South Africa, 8000.

McALISTER T (2007) National guidelines for evaluating water sensitive urban design (WSUD). Office Report R B16789.001.00.doc. BMT WBM Pty Ltd, Queensland, Australia.

McGOWN D (2011) Personal communication, 23 February 2011. Ms Diane McGown, George Local Municipality, Western Cape Province, South Africa, 6529.

McKUNE C (2009) Amid wet week, drought to persist. URL: http:// www.iol.co.za/news/south-africa/amid-wet-week-drought-topersist-1.457771? ot=inmsa.ArticlePrintPageLayout.ot (Accessed 25 August 2011).

MISHRA AK and SINGH VP (2010) A review of drought concepts. J. Hydrol. 391 202-216.

MITCHELL VG (2006) Applying integrated urban water management concepts: A review of Australian experience. Environ. Manage. 37 (5) 589-605.

MOOIMAN L (2010) Personal communication, 14 January 2010. Ms Lindsay Mooiman, George Local Municipality, Western Cape Province, 6529.

MORISON PJ and BROWN RR (2011) Understanding the nature of publics and local policy commitment to water sensitive urban design. Landscape Urban Plann. 99 (2) 83-92.

NEL C (2010) Personal communication, 04 August 2010. Mr Coenraad Nel, George Local Municipality, Western Cape, 6529.

NEWMAN P (2001) Sustainable urban water systems in rich and poor cities. Steps towards a new approach. Water Sci. Technol. 43 (4) 93-99. 
SHARMA SK and VAIRAVAMOORTHY K (2010) Urban water demand management: prospects and challenges for the developing countries. Water Environ. J. 23 (3) 210-218.

SPEERS A and MITCHELL G (2000) Integrated urban water cycle. Paper delivered at Conference on Water Sensitive Urban DesignSustainable Drainage Systems for Urban Areas, 30-31 August 2000, Melbourne, Australia. URL: http://www.yemenwater.org/wpcontent/uploads/2013/04/Integrated-Urban-Water-Cycle-Mitchell. pdf (Accessed June 2010).

SUMMERS R (2010) Personal communication, 22 November 2010. Ms Rene Summers, Department of Water Affairs, Western Cape Province, South Africa, 8000.

TAM VWY, TAM L and ZENG SX (2010) Cost effectiveness and tradeoff on the use of rainwater tank: An empirical study in Australian residential decision-making. Resour. Conserv. Recy. 54 178-186.

TEMPELHOFF J, VAN NIEKERK D, VAN EEDEN E, GOUWS I, BOTHA K and WURIGE R (2009) The December 2004 - January
2005 floods in the Garden Route region of the Southern Cape, South Africa. J Disaster Risk Stud. 2 (2) 93-112.

THOMAS R and THOMAS M (2003) Green Roofs for Sustainable Cities - Sustainable Cities 2025. Project no. GR-311003-1. Report delivered to Standing Committee on Environment and Heritage October 2003, House of Representatives, Parliament of Australia.

VECK GA and BILL MR (1998) Estimation of the residential price elasticity of demand for water by means of a contingent value approach. WRC Report No. 790/1/00. Water Research Commission, Pretoria.

WESTERN CAPE PROVINCE (2009) Provincial Gazette. 20 November, No 6677. Western Cape Provincial Government, Cape Town.

WOLFE SE (2009a) What's your story? Practitioners' tacit knowledge and water demand management policies in southern Africa and Canada. Water Polic. 11 489-503.

WOLFE SE (2009) A social innovation framework for water demand management Policy: practitioners' capabilities, capacity, collaboration, and commitment. Soc. Nat. Resour. 22 (5) 474-483. 
http://dx.doi.org/10.4314/wsa.v41i1.1 Available on website http://www.wrc.org.za

ISSN 0378-4738 (Print) = Water SA Vol. 41 No. 1 January 2015 ISSN 1816-7950 (On-line) = Water SA Vol. 41 No. 1 January 2015 